\title{
PESQUISA INTERVENÇÃO FORMATIVA NA ESCOLA: POSSIBILIDADES DE TRANSFORMAÇÃO HUMANA E SOCIAL.
}

\author{
Fabiane Salomão Souza, Irineu Aliprando Tuim Viotto Filho \\ Universidade Estadual Paulista - UNESP, Programa de Pós-graduação em Educação, Presidente Prudente, SP. E-mail: \\ salomaopsico@yahoo.com.br
}

\begin{abstract}
RESUMO
Este trabalho apresenta alguns resultados obtidos de uma dissertação de mestrado, considerando a realização de uma pesquisa intervenção formativa desenvolvida em 2016 numa escola da rede municipal de Educação de Presidente Prudente/SP. Os sujeitos foram as gestoras, professores do Ensino Fundamental e os estudantes de uma sala de aula do 3 ano do Ensino Fundamental. Neste trabalho abordaremos resultados obtidos com o processo realizado junto aos estudantes, por meio de análise das entrevistas semiestruturadas realizadas junto as gestoras da escola e professora da sala de aula. As respostas apontam mudanças qualitativas nos estudantes em relação as suas ações com os outros na escola, avanços na aprendizagem e desenvolvimento e pertencimento ao grupo. O processo de intervenção formativa baseou-se nos fundamentos da teoria histórico-cultural. Foram realizadas atividades ludo-pedagógicas com os estudantes buscando proporcionar um espaço de aprendizagem crítica e rompendo com modelo clínico de atuação, focando o trabalho nas potencialidades.
\end{abstract}

Palavras chave: Educação. Psicologia. Pesquisa Intervenção Formativa. Teoria histórico-cultural. Psicologia histórico-cultural.

\section{RESEARCH TRAINING INTERVENTION IN SCHOOL: POSSIBILITIES OF HUMAN AND SOCIAL TRANSFORMATION.}

\begin{abstract}
This work presents some results obtained in a master's thesis, from the conduction of an formative intervention research developed in a school of education in the city of Presidente Prudente /SP, in the year 2016. The subjects were the managers, teachers of Elementary School and the students of a 3rd year classroom of School. In this work we will discuss the results obtained with the students' process, through the analysis of the answers given by the managers and the student teacher during a interview. The answers point to qualitative changes in the students in relation to their actions with others in the school, improvement of learning and development and group belonging at school. The process of formative intervention was based on the foundations of historical-cultural theory where ludo-pedagogical activities were carried out with the students seeking to provide a learning space breaking with clinical model of action and focusing their potentialities.

Keywords: Education. Psychology. Research Formative Intervention. Historical-cultural theory. Historical-cultural psychology.
\end{abstract}




\section{INTRODUÇÃO}

A Educação configura-se com um campo de muitas disputadas e lutas, envolvendo concepções ético-políticas diversas e explicações teóricas diferentes acerca do desenvolvimento humano. Temos verificado em estudos de autores como Silva Jr. (2016), Saviani e Duarte (2012) que a visão empresarial têm causado impacto e transformando de forma negativa as relações no interior da escola. Esta visão segue a lógica do mercado e não a lógica do direito à Educação, respondendo aos interesses da sociedade capitalista e assim, responsabilizando o indivíduo pelo seu desempenho. Na mesma direção crítica, Moysés e Collares (1994; 2013), explicitam a ideologia liberal presente nas concepções biologizantes sobre o desenvolvimento humano e que estimulam o processo de patologização e medicalização dos processos educacionais, como exposto no Fórum sobre Medicalização da Educação e da Sociedade (2010).

$\mathrm{Na}$ defesa de uma Educação escolar voltada a transformação humana e social, apresentamos neste trabalho, alguns resultados obtidos em uma dissertação de mestrado Souza (2017), quando da realização de um processo de pesquisa-intervenção no interior de uma escola da rede municipal de Educação de Presidente Prudente/SP, no qual buscou-se romper com concepções naturalizantes e a-históricas sobre o desenvolvimento humano, como afirma Meira (2014). Aquela pesquisa propôs a criação de um "espaço" diferenciado de aprendizagem para os estudantes de uma sala de aula do 3o. ano do Ensino fundamental, a partir da mediação de atividades ludo-pedagógicas, com o objetivo de engendrar ações e evidenciar as potencialidades de aprendizagem e desenvolvimento do grupo de estudantes da citada sala de aula. Entendemos por atividade ludo-pedagógica, aquela organizada intencionalmente e devidamente orientada pelo professor, que valoriza a ludicidade no processo de aprendizagem da criança, de forma a tornar a relação ensino e aprendizagem mais coerente com o período de desenvolvimento psicomotor da criança. Salientamos que por nos basearmos na teoria histórico-cultural, em nenhum momento da intervenção houve a preocupação em classificar ou diagnosticar os estudantes, mas sim, realizar ações evidenciando suas potencialidades, considerando o vir-à-ser desses sujeitos na escola, como afirma Oliveira (1996).

\section{METODOLOGIA}

A pesquisa intervenção formativa foi realizada com os estudantes de uma sala de aula do 3o ano, do ensino fundamental, ciclo I. As intervenções se respaldaram nos pressupostos teóricos da teoria histórico-cultural, assim como da pedagogia histórico-crítica e, na mesma direção crítica, assumimos o conceito de "intervenção-formativa", oriundo de estudos realizados acerca do trabalho de Vasili Davidov (1920-1998) na Rússia. A pesquisa foi autorizada pelo comitê de ética em pesquisa, com número de protocolo 109/2009. Esta sala foi indicada pela direção da escola por ser composta por estudantes com problemas de aprendizagem, defasagem de conteúdos escolares, dificuldades na leitura, escrita e cálculos matemáticos, além de problemas de agressividade e indisciplina, sendo que alguns estudantes tinham diagnosticados de Transtorno do Déficit de Atenção e Hiperatividade (TDAH). A sala era formada por 15 estudantes, sendo 03 do sexo feminino. Nos encontros de intervenção foram realizadas atividades ludo-pedagógicas, com objetivo de possibilitar o conhecimento sobre os sentimentos e as emoções, processo de identidade, melhora nas relações sociais, noção de pertencimento ao grupo, desenvolvimento qualitativo das funções psicológicas superiores como atenção, memória, imaginação, linguagem e pensamento. No geral, a proposta de intervenção objetivou estimular a aprendizagem e o desenvolvimento dos estudantes de forma global, assim como o enfrentamento e superação das dificuldades escolares. 


\section{RESULTADOS}

Para apresentar os resultados obtidos com o processo de pesquisa-intervenção, destacamos alguns aspectos que foram analisados em nossa dissertação de mestrado, a partir de excertos das entrevistas das gestoras e da professora dos estudantes sujeitos da pesquisa. Destacamos os aspectos relativos às "contribuições do processo para sua prática", "dificuldades dos estudantes", "opiniões sobre o processo" e as "contribuições gerais da pesquisa-intervenção". A diretora da escola ressalta que houve mudanças na forma dos professores olharem para os estudantes, pois antes trabalhavam de forma a não considerar suas particularidades e conhecimentos. Esta mudança possibilitou a superação dos rótulos de "aluno problema ou com dificuldade" e, simultaneamente, que os próprios estudantes se reconhecessem no mesmo plano que outros estudantes da escola. A professora da sala enfatizou os conhecimentos socializados nos encontros de intervenção, considerando-os como fundamentais para qualificar sua prática pedagógica. Ainda enfatizou as conquistas dos estudantes que superaram suas dificuldades em relação a leitura e escrita, interação social e timidez. Ela afirmou que o processo realizado permitiu que os estudantes se tornassem "protagonistas de sua própria história". As gestoras destacam a relevância do processo de intervenção com atividades ludo-pedagógicas realizado junto aos estudantes, não apenas como forma de obtenção de dados, mas por possibilitar a criação de um "espaço" diferenciado para a manifestação e expressão dos estudantes na escola.

\section{DISCUSSÃO}

Em relação as contribuições do processo, a diretora destaca a importância em entender que os estudantes são diferentes, que eles são sujeitos singulares. Esta visão particularizada de cada estudante foi enfatizada nos estudos de casos e nos momentos de discussão e reflexão junto ao grupo de professores e gestores. Levamos para o grupo as reflexões de que o estudante é um sujeito histórico-social e faz parte do trabalho do professor considerar essa história, Souza (2010, p.145) afirma

Essa história é a história do sujeito escolar e seu resgate envolve a consideração de questões, tais como: Quem é este sujeito escolar? De onde veio? Como estudou? Que oportunidades teve? Por quais professores passou em sua trajetória? Como se deu essa relação?

$\mathrm{Na}$ visão da diretora, os professores e a escola pública em geral, trabalham com os estudantes de forma padronizada, desconsiderando suas particularidades e seus conhecimentos prévios. Estas afirmações vêm ao encontro das reflexões de Franco (2009, p. 5184) quando afirma que

[...] as dificuldades de aprendizagem são, em sua ampla maioria, fruto de inadequações de ensino. O professor, muitas vezes constrói um ideal de aluno que acaba por afastá-lo da realidade concreta da sala de aula. È necessário conhecer os sentidos e significados que o professor construiu ao longo de sua trajetória ao trabalho educativo. Trabalhar com estas significações pode trazer a possibilidade de transformação da pratica pedagógica.

Diante destas afirmações, destacamos a opinião das gestoras da escola:

Contribuição primeiro que cada aluno, esse olhar nosso é diferenciado, porque cada aluno, ele é único, nós não podemos pensar o aluno como um todo da escola, cada aluno, quando ele vem pra escola, ele já trás o seu conhecimento, ele já trás, é que muitas vezes, a gente acaba ignorando isso, o professor acaba ignorando, o diretor acaba ignorando, por que? Porque a gente acaba tratando ali todos os alunos, como se eles estivessem em pé de igualdade, inclusive o nosso vocabulário, o nosso linguajar que muitas vezes, acaba sendo distante da realidade de nossos alunos, e isso foi importante para gente parar, pensar e 
refletir, por exemplo, as crianças quando tinham dificuldade de aprendizagem [...] (Diretora, informação verbal, 2017, grifos nossos).

A respeito das Contribuições do processo de pesquisa- intervenção em sua prática, a professora ressalta que

Trouxe bastante conhecimento, como eu já disse, foi uma capacitação, e é o conhecimento que a gente leva para toda vida, a gente vai levar e vai realizando ali, na sala de aula com os alunos, é tenta ali, tentando arrumar, fazer o melhor, o máximo que a gente pode, trabalhando ali a realidade dos alunos, a dificuldade de cada um, então é o conhecimento que a gente traz para a vida, é pra vida (Professora do 3o ano, informação verbal, 2017, grifos nossos).

Salientamos que as dificuldades apresentadas pelos estudantes da sala de aula do 3음 ano eram várias, segundo os relatos das gestoras, tinham problemas no processo de aquisição da leitura e escrita, indisciplina, problemas na linguagem oral e encontravam-se muito desmotivados. Chama-nos atenção o fato da sala de aula ser composta em sua maioria por meninos, o que nos faz relacionar com as afirmações de Souza (1997, p. 23) "os encaminhamentos em função de dificuldades na escolarização formal têm em comum uma questão de gênero: os meninos são mais frequentemente encaminhados para o atendimento psicológico". Como os estudos têm demonstrado, as queixas de dificuldades de aprendizagem, em sua maioria, são de meninos e a sala de aula pesquisada representa um retrato dessa realidade. A queixa aparece configurada na fala das gestoras, conforme abaixo:

[...] eram alunos desmotivados, nós tínhamos lá um aluno que ele dormia o tempo inteiro em sala de aula, era assim até uma fuga, porque ele não sabia fazer nada, ele acabava dormindo e a gente perguntava, alunos que tinham dificuldade na linguagem oral, até pra se expressar, é... e muitos deles se negavam fazer qualquer tipo de atividade, eles se mantinham com o caderno fechado [...](Diretora, informação verbal, 2017, grifos nossos).

Eram crianças que não estavam alfabetizadas, então a gente tinha dois problemas, crianças que não estavam alfabetizadas e com isso, muitas delas tinham problemas de indisciplina, então, nessa sala o problema também foi crianças com dificuldade na leitura e escrita e ainda algumas com a indisciplina (Orientadora pedagógica, informação verbal, 2017, grifos nossos).

A professora da sala de aula destaca algumas dificuldades dos estudantes, leitura e escrita, interação social e timidez. Destacamos a afirmação de Franco (2009), sobre a produção de significações que pelo processo de apropriação, tornam-se constitutivas dos sujeitos. Neste sentido, consideramos que as dificuldades nos estudantes do 3ㅇ ano foram internalizadas a partir de práticas realizadas no espaço escolar e em suas vidas. Destacamos Franco (2009, p. 5181)

$\mathrm{O}$ homem é naturalmente humano. Existe um eixo de normalidade e aqueles que não foram neste plano inseridos devem ser diagnosticados, classificados para receberem o devido tratamento. Temos neste caso a produção de patologias que vão se imprimindo e tornando-se constitutivas da aluna [dos estudantes do 3 응 ano]. Consideramos de fundamental importância ressaltar que a atividade partilhada é responsável por produzir significações que, ao serem apropriadas, criam o plano do sujeito, ou seja, sua consciência.

A diretora avalia que o processo ludo-pedagógico de intervenção com os estudantes possibilitou que eles se vissem como os demais estudantes da escola, "que eles eram iguais a todos os alunos porque até então eles se sentiam diferentes, que eram alunos com dificuldade"; 
vemos nestas palavras o quanto os estudantes haviam incorporado os rótulos de crianças com problemas de aprendizagem. Diante dos resultados obtidos nos encontros com estudantes, podemos refletir que as crianças da sala de aula pesquisada, a partir do momento que Ihes foi possibilitado um "espaço" diferenciado de aprendizagem, no sentido de que foram depositadas novas expectativas, novos estímulos e foram disponibilizadas atividades lúdicas de natureza educativa, não dirigidas especificamente para alfabetização, mas com objetivos diversificados e atendendo necessidades diversificadas, responderam adequadamente e se transformaram nesse processo. Destacamos as palavras da diretora da escola sobre os encontros de intervenção com a sala de aula:

Eu sempre fui apaixonada pelo trabalho, falo que eu sou até suspeita em falar porque, porque era o dia que eu percebia que as crianças vinham com mais satisfação na escola [...]essas intervenções agradavam os alunos, eles ficavam felizes e com essa felicidade eles podiam, é eles percebiam que eles eram iguais a todos os alunos, porque até então eles se sentiam diferentes, que eram alunos com dificuldade[...]eu percebi que a autoestima deles melhorou muito [...](Diretora, informação verbal, 2017, grifos nossos).

Quanto a opinião da professora sobre o processo de intervenção, ela o avalia como positivo e importante para os estudantes da sala de aula. A professora não identifica nenhum ponto negativo no processo e destaca que a sala "melhorou bastante, tanto a interação entre eles, quanto a leitura e escrita, aprendizagem, com isso já valeu tudo". A respeito das melhoras apresentadas pelos estudantes, destacamos como a Psicologia histórico-cultural entende o processo de desenvolvimento do psiquismo humano.

Para a Psicologia Histórico-Cultural, as funções psicológicas superiores existem concretamente na forma de atividade interpsíquica nas relações sociais antes de assumirem a forma de atividade intrapsíquica. Mediante o processo de internalização ocorre a transformação do conteúdo das relações sociais em funções psicológicas superiores, especificamente humanas (TULESKI; EIDIT, 2007, p. 532).

A diretora ressalta que o processo de intervenção, tanto com os professores, como com os estudantes, aconteceu de forma positiva e a orientadora destaca um aspecto importante dos encontros de intervenção realizados na escola, o fato de propor atividades ludo-pedagógicas aos estudantes. Ressaltamos suas opiniões

[...] esse trabalho veio sim a auxiliar os professores, porque não bastava só culpar a família, ou os professores, a gente pensava, e precisava pensar em estratégias para conseguir atender a todos os alunos, esse é o principal objetivo da escola, atender todos os alunos (Diretora, informação verbal, 2017).

[...] a escola contribuir com a universidade e vice-versa! Porque não é só universidade ir lá colher dados, é ir, fazer uma intervenção e as crianças são beneficiadas com isso (Orientadora pedagógica, informação verbal, 2017, grifos nossos).

Os encontros de intervenção com os estudantes possibilitaram qualitativamente mudanças nas relações sociais escolares e, simultaneamente, no desenvolvimento do indivíduos, pois foram elaborados segundo a teoria histórico-cultural, sendo que, para Franco (2009) essa perspectiva

[...] entende o homem enquanto ser sócio-histórico, isto é, crê que o homem seja um ser concreto, social, histórico e cultural, que constrói sua humanidade na interação com outros homens, onde os processos psicológicos não são dados e, sim, construídos nesta rede (FRANCO, 2009, p. 5181). 
Destacamos as afirmações da professora que sintetizam os resultados:

[...] foi bem importante, tanto pro profissional, quanto pros alunos, e pra eles, foi muito bom, se sentiram assim, a maneira como foi aplicado as aulas, e eles se sentiam importantes, a cada atividade, finalizando com o teatro, a palavra assim que fecha é que eles se tornaram protagonistas de sua própria história , então isso pra mim , nossa, foi muito importante mesmo, contribuiu bastante pra gente, profissional, como pro aluno (Professora do 3ำ ano, informação verbal, 2017, grifos nossos).

\section{CONCLUSÕES}

Concluímos que o processo de pesquisa-intervenção formativa possibilitou o desenvolvimento qualitativo dos estudantes em relação ao processo de aprendizagem da leitura e escrita, melhorou as relações sociais entre os estudantes e com demais sujeitos da escola. As queixas de problemas de agressividade, indisciplina diminuíram e os estudantes começaram formar o conceito de pertencimento ao grupo. O autoconceito e autoestima se transformaram, tendo como consequência a melhoria de suas relações com o conhecimento, com os colegas e com a própria escola. Neste sentido, verificamos que a intervenção de profissionais especializados no espaço da escola, a partir de uma concepção histórico-social do desenvolvimento humano, supera visões e atuações biologizantes e preconceituosas, podendo engendrar transformações sociais e humanas na escola.

\section{REFERÊNCIAS}

COLLARES, C. L., ; MOYSÉS, M. A. A. A transformação do espaço pedagógico em espaço clínico (A Patologização da Educação). Série Ideias (23), São Paulo, FDE, 25-31, 1994.

COLLARES, C. L., ; MOYSÉS, M. A. A. Controle e medicalização da infância: controlar é preciso. Número 1 ano 1.Temas em destaque. 2013. Disponível em: https://revistas.ufrj.br/index.php/desidades/article/viewFile/2456/2090. Acesso em: 03 de maio de 2017.

DAVIDOV, V. La enseñanza escolar y El desarrollo psiquico. Tradução de Marta Shuare. Moscou: Progresso, 1988.

FRANCO, A. F. Reflexões em torno do encaminhamento da queixa escolar e a produção do fracasso escolar franco In: IX Congresso Nacional de Educação - EDUCERE- PUC, PR. p. 5181-5187, 2009.

MACHADO, A. M. ; SOUZA, M. P. R. (Orgs.). Psicologia Escolar: em busca de novosrumos. São Paulo: Casa do Psicólogo, 1997.

MEIRA, M.E.M. Prefácio In: LEONARDO, N.S.T.;LEAL, Z.F.R.G.;FRANCO, A.F. (Orgs.).Oprocesso de escolarização e a produção da queixa escolar: reflexões a partir de uma perspectiva crítica em psicologia. Maringá: Eduem, 2014.

OLIVEIRA, B. O Trabalho Educativo. Campinas: Autores Associados, 1996.

SAVIANI. D. DUARTE. N. (Orgs.). Pedagogia histórico-crítica e luta de classes na educação escolar. Campinas: Autores Associados. 2012. 
I Seminário Internacional "A Educação Medicalizada: Dislexia, TDAH e outros supostos transtornos". Fórum sobre Medicalização da Educação e da Sociedade. São Paulo, 2010. Disponível em: http://medicalizacao.org.br/tag/secadi/. Acesso em: 13 de agosto de 2017.

SILVA Jr, C. A. A escola pública como objeto de estudo. Revista Pesquisa Qualitativa. V.4, no 4. 2016. Disponível em: http://rpq.revista.sepq.org.br/index.php/rpq/article/view/32. Acesso em: 10 de junho de 2017.

SOUZA. M. P. R. Psicologia Escolar e políticas públicas em Educação: desafios contemporâneos. Em Aberto, Brasília, v. 23, n. 83, p. 129-149, 2010. Disponível em: emaberto.inep.gov.br/index.php/emaberto/article/viewFile/2255/2222. Acesso em: 04 de maio de 2017.

SOUZA, F. S. Processo de intervenção histórico-cultural na escola: dialogando com gestores, professores e estudantes. Dissertação de mestrado. Programa de Pós-graduação em Educação. Universidade Estadual Paulista. Faculdade de Ciências e Tecnologia, Presidente Prudente, SP, 2017. $239 f$.

TULESKI, S. C.; EIDT, N. M. Repensando os distúrbios de aprendizagem a partir da psicologia histórico-cultural. Psicologia em Estudo, Maringá, v. 12, n. 3, pp. 531-540.set./dez., 2007. https://doi.org/10.1590/S1413-73722007000300010. 